\title{
Poly(ethyleneimine) modified filters for the removal of leukocytes from blood
}

\author{
Anton Bruil, ${ }^{1}$ Hieke A. Oosterom, ${ }^{1}$ Ingeborg Steneker, ${ }^{2}$ Bert J. M. Al, ${ }^{2}$ Tom \\ Beugeling, ${ }^{1}$ Willem G. van Aken, ${ }^{1,2}$ and Jan Feijen ${ }^{1, *}$ \\ ${ }^{1}$ Department of Chemical Technology, Biomaterials Section, University of Twente, P.O. Box 217, 7500 AE Enschede, \\ The Netherlands; and ${ }^{2}$ Central Laboratory of the Netherlands Red Cross Blood Transfusion Service, P.O. Box 9190, \\ 1006 AD Amsterdam, The Netherlands
}

Polyurethane membrane filters and filters coated with poly(ethyleneimine) were used to investigate the influence of leukocyte adhesion during filtration. Treatment of the filters with an aqueous solution of $1 \%$ $(w / v)$ poly(ethyleneimine) (PEI) led to the introduction of amine groups at the filter surfaces, as was confirmed by X-ray photoelectron spectroscopy. The modification procedure did not significantly change the porous structure in the filters, as was demonstrated by SEM and porometry. Using ${ }^{14} \mathrm{C}$-labeled poly(ethyleneimine) it was shown that nearly a complete coverage $\left(\sim 0.1 \mathrm{mg} / \mathrm{m}^{2}\right)$ was achieved that did not desorb from the filter surface during contact with blood plasma. When the filtration was carried out with purified leukocytes in the absence of red cells, platelets, and blood plasma, the number of cells removed by modified filters $(>95 \%)$ was signifi- cantly higher as compared to the removal with unmodified filters $(\sim 80 \%)$. However, no significant differences between the filters were found when the filtration was performed with whole blood. This finding was unexpected, because it was shown before that immobilization of poly(ethyleneimine) on solid polyurethane film, surfaces promoted the adhesion of leukocytes from whole blood. Apparently, the adhesive properties of the PEI diminish during filtration. Filter coating of commercial leukocyte filters composed of polyester fibers also had no effect on the removal of leukocytes from whole blood. It was postulated that morphological factors, such as filter shape, roughness, tortuosity, and porosity rather than the physicochemical properties of the filter surface influence cell adhesion to the filter surface, and through that the filtration process. (c) 1993 John Wiley \& Sons, Inc.

\section{INTRODUCTION}

Leukocyte depleted blood products, particularly red-cell concentrates, are clinically used to avoid negative side effects in recipients after transfusion. Such leukocyte-associated post-transfusion complications include human leukocyte antigen (HLA) alloimmunization, graft-versus-host disease, platelet refractoriness, and transmission of viruses. ${ }^{1}$ Amongst the various techniques to remove leukocytes from blood, filtration has become a popular method because of its convenience and low costs. ${ }^{2}$ Leukocyte filters have been specially developed for this purpose and they generally consist of fibrous materials made of nylon, ${ }^{3}$ polyacrylonitrile, ${ }^{4}$ cotton wool, ${ }^{5}$ cellulose acetate, $^{6}$ or polyester. ${ }^{7,8}$ Currently available filters remove more than $99 \%$ of the leukocytes from whole blood, while red cell loss is small. ${ }^{9}$

*To whom correspondence should be addressed.
Much has been speculated about the mechanism of leukocyte depletion by these filters. Several authors have propounded that the removal of leukocytes is accomplished by selective adhesion of leukocytes to the filter material. $8,10,11$ In a previous study on the mechanisms of leukocyte filtration, in which polyurethane (PU) membranes were used as model filters, it was demonstrated that adhesion rather than mechanical sieving governs the filtration process. ${ }^{12}$ Similar results have been reported by Steneker and Biewenga who studied a commercially available filter type. ${ }^{6,7}$ However, the quantitative effect of leukocyte adhesion on the efficacy of leukocyte filters was not conclusively tested since the observations were based on studies in which only one particular type of filter was used. In order to demonstrate the relationship between leukocyte adhesion and leukocyte removal, structurally equivalent filters that have different surface properties with respect to leukocyte adhesion should be compared. Such model filters may be prepared by surface 
modification of leukocyte filter materials with a well defined porous structure. ${ }^{12}$

In order to optimize leukocyte adhesion to PU membrane filters, we have previously studied the effect of ionizable functional groups ${ }^{13}$ and wettability ${ }^{14}$ on the in vitro adhesion of leukocytes to modified PU films under static conditions. Of all surfaces tested, the number of adherent leukocytes as a function of time was highest for the PU surfaces modified with poly(ethyleneimine) (PEI). This was explained by short range interactions between amine groups of the immobilized PEI and specific groups at the cell surface of leukocytes. When the efficacy of PEI modified solid films was studied under flow conditions, the difference between unmodified and PEI modified PU surfaces with respect to leukocyte adhesion was maintained, although the absolute number of adherent cells was highly dependent on the flow rate, and the presence or absence of $\mathrm{Ca}^{2+}$ and $\mathrm{Mg}^{2+}$, plasma, and platelets in the cell suspension medium. ${ }^{15}$ PEI modification thus offers the possibility to prepare PU membrane filters to which leukocyte adhesion is increased as compared to unmodified filters.

The cell adhesive properties of PEI modified surfaces are well known in cell biology, and have been explored in chemotherapy, ${ }^{16}$ cell diagnostic procedures, ${ }^{17}$ biotechnology, ${ }^{18}$ and water purification. ${ }^{19}$ Applications of a PEI coating to improve filter media, e.g., cigarette filters, ${ }^{20}$ cation exchange membranes, ${ }^{21}$ and specific filters for protein binding, ${ }^{22}$ have also been reported. Up to now, however, the use of PEI to improve leukocyte adhesion to filter materials has not been reported.

The aim of the present study was to compare the leukocyte removal efficacy of PEI modified and unmodified filters, in order to elucidate the relationship between leukocyte adhesion and leukocyte filtration. The stability of the PEI coating on modified filters was studied using ${ }^{14} \mathrm{C}$-labeled PEI. To test the hy- pothesis that the filter efficacy is related to the extent of leukocyte adhesion, we have performed filtration experiments with purified granulocyte suspensions in phosphate buffered medium. In this way a direct comparison with the previous results of in vitro leukocyte adhesion studies ${ }^{13}$ is possible. In addition, standard blood filtration experiments were performed with both PU membrane filter and commercial filters, either PEI modified or unmodified.

\section{MATERIALS AND METHODS}

\section{Membrane preparation}

Series of polyurethane (PU) membrane filters were prepared from medical grade Pellethane 2363-80AE (Dow Chemical Nederland BV, Delfzijl, The Netherlands), using standard salt suspension techniques. ${ }^{12}$ To remove low molecular weight fractions, the polymer was first purified by slowly adding a $5 \%(\mathrm{w} / \mathrm{v})$ solution of PU in dimethylformamide (DMF) to a 10fold excess of water whilst stirring at high speed. The precipitate was collected by filtration, and dried in vacuo at $60^{\circ} \mathrm{C}$.

Membranes with relatively small pores (type 15.1; Table I) were prepared from a solution of $9 \%(\mathrm{w} / \mathrm{v})$ PU in DMF in which $75 \%(\mathrm{v} / \mathrm{v}$, with respect to $\mathrm{PU})$ of powdered magnesium carbonate, (Janssen, Beerse, Belgium), particle size $<1 \mu \mathrm{m}$, was suspended. The suspension was treated ultrasonically for at least 1 day to break down particle aggregates. After degassing, thin films $(500 \mu \mathrm{m})$ were cast from these suspensions on clean glass plates, after which the PU was coagulated by immersing the plates in ethanol for $20 \mathrm{~min}$. Thereafter, the salt particles were dissolved by extraction with $3 \mathrm{M}$ hydrochloric acid.

Membranes with larger pores (types 15.2, 15.3, and 15.4; Table I) were prepared from solutions of PU in

TABLE I

Porous Structure of Filter Materials Used

\begin{tabular}{|c|c|c|c|c|c|c|c|c|}
\hline \multirow[b]{2}{*}{ Sample } & \multicolumn{4}{|c|}{ Before Modification } & \multicolumn{4}{|c|}{ After PEI Modification } \\
\hline & Porosity $(\%)$ & $d_{\mathrm{av}}(\mu \mathrm{m})$ & $d_{\text {bottom }}(\mu \mathrm{m})$ & $d_{\mathrm{top}}(\mu \mathrm{m})$ & Porosity $(\%)$ & $d_{\mathrm{av}}(\mu \mathrm{m})$ & $d_{\text {bottom }}(\mu \mathrm{m})$ & $d_{\text {top }}(\mu \mathrm{m})$ \\
\hline 13 & 92.5 & $20 \pm 3$ & $21 \pm 11$ & $31 \pm 17$ & 92.1 & $23 \pm 1$ & $22 \pm 11$ & $33 \pm 18$ \\
\hline 14 & 86.8 & $30 \pm 1$ & $21 \pm 5$ & $35 \pm 14$ & * & * & & * \\
\hline 15.1 & 69.8 & $7 \pm 2$ & $9 \pm 2$ & $11 \pm 5$ & 67.2 & $7 \pm 1$ & $11 \pm 4$ & $20 \pm 7$ \\
\hline 15.2 & 91.1 & $22 \pm 1$ & $24 \pm 6$ & $32 \pm 11$ & 84.6 & $17 \pm 1$ & $28 \pm 8$ & $36 \pm 12$ \\
\hline 15.3 & 92.2 & $27 \pm 2$ & $35 \pm 9$ & $45 \pm 16$ & 90.2 & $24 \pm 1$ & $36 \pm 12$ & $44 \pm 18$ \\
\hline 15.4 & 92.1 & $38 \pm 1$ & $60 \pm 12$ & $104 \pm 34$ & 89.0 & $31 \pm 1$ & $56 \pm 13$ & $81 \pm 18$ \\
\hline 16 & 90.8 & $23 \pm 4$ & $27 \pm 7$ & $41 \pm 13$ & 91.6 & $26 \pm 2$ & $28 \pm 7$ & $32 \pm 12$ \\
\hline Fine $^{t}$ & & $9 \pm 1$ & & & & $9 \pm 1$ & & \\
\hline Coarse $^{t}$ & & $28 \pm 3$ & & & & $29 \pm 4$ & & \\
\hline
\end{tabular}

${ }^{*}$ Not determined; membranes used in ${ }^{14} \mathrm{C}$-PEI studies.

${ }^{\dagger}$ Representing nonwoven layers from coarse and fine filter sections of the commercial PET filters used. 
DMF $(7 \%, \mathrm{w} / \mathrm{v})$ in which particles of sodium citrate (Janssen, Beerse, Belgium) with size distributions of 0-38 $\mu \mathrm{m}, 38-63 \mu \mathrm{m}$, and 63-106 $\mu \mathrm{m}$, respectively, were suspended. Particle fractions with these distributions were obtained by sieving. For the respective membranes, the concentration of particles used was 88,89 , and $90 \%$ (v/v, with respect to PU). Films of these suspensions were prepared and coagulated as described above. The salt particles were removed by washing with water.

Membrane type 13 was prepared as described for membrane type 15.2 , and membrane type 14 and 16 were prepared as described for membrane type 15.3. In Table I further information about the membrane characteristics are given.

After preparation, all membranes were washed with distilled water, rinsed in ethanol, and finally dried in air. Membranes were kept dry in the dark at room temperature.

\section{Filter preparation}

Model filters were prepared by stacking membranes described in the membrane preparation section. First, thin filter layers with a diameter of $50 \mathrm{~mm}$ were cut from a stack of 4-5 membranes. Several of these layers, with a total thickness of $\sim 3 \mathrm{~mm}$, were then mounted together in a special polycarbonate filter housing (Schleicher \& Schüll, type FP 050/0). To achieve sufficient filter capacity, two of these filter units were connected (Fig. 1). Both symmetric and asymmetric filters were prepared. Symmetric filters were composed of identical membranes in order to obtain a uniform pore size distribution, typically $\sim 25 \mu \mathrm{m}$, throughout the filter. Asymmetric filters were composed of a stack of different membranes, in such a way that the average pore size decreased in the direction of blood flow through the filter. These filters were arbitrarily composed as follows; 4 times type 15.4, 12 times type 15.3, 4 times type 15.2, and 5 times type 15.4, respectively.

Commercially available Optima Cellselect leukocyte filters (NPBI, Emmer-Compascuum, The Netherlands) were used to investigate PEI filter modification during routine blood filtration. These filters consist of poly(ethylene terephthalate) (PET) fibers and can be subdivided in three different compartments, i.e., a prefilter, a course main filter, and a fine main filter, varying in thickness, fiber size, and porous structure.

\section{Filter modification}

Before modification, filters described in the filter preparation section were first thoroughly rinsed with distilled water for $30 \mathrm{~min}(2.5 \mathrm{~mL} / \mathrm{sec})$. Coating with poly(ethyleneimine) (PEI 600; mol. weight 40,000-

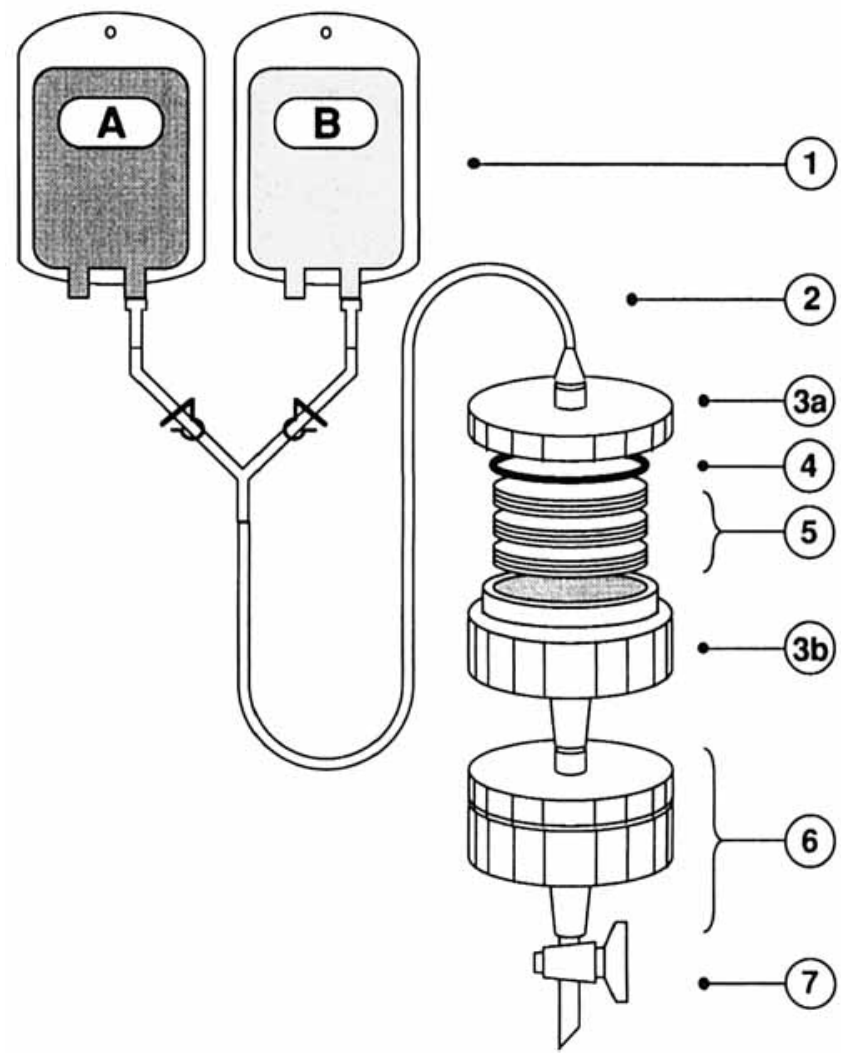

Figure 1. Schematic representation of the experimental filtration set-up. (1) reservoir bags with (A) cell suspension and (B) saline, (2) PVC tubing with closing clips, $(3 \mathrm{a} / \mathrm{b})$ polycarbonate filter housing, (4) silicone rubber ring, (5) filter layers, each composed of 4-5 membranes, (6) second filter unit, and (7) outlet valve.

60,000; Sigma, St. Louis, MO) was achieved by slowly perfusing the filters with a solution of $1 \%(\mathrm{w} / \mathrm{v})$ PEI in distilled water $(\mathrm{pH} 11)$ for $1 \mathrm{~h}(0.5 \mathrm{~mL} / \mathrm{sec})$. Weakly adsorbed PEI was removed by rinsing with distilled water followed by rinsing with phosphate buffered sodium chloride solution (PBS) for 5 min each $(2.5 \mathrm{~mL} / \mathrm{sec})$. The coated filters were then thoroughly washed with distilled water for $1 \mathrm{~h}(2.5 \mathrm{~mL} / \mathrm{sec})$. To dry the filters, they were removed from the filter housing and exposed to air. Commercial filters were flushed overnight with clean dry air until their weight remained constant.

Control filters, which will be referred to as unmodified, were treated as described above, except that the PEI solution was replaced by distilled water. All filters were stored dry in the dark at room temperature until use.

\section{Characterization of the filter structure}

Surfaces and cross-sections of the membranes were examined by scanning electron microscopy (SEM; Jeol, type JSM-35 CF). Pore size distributions were de- 
termined in duplo by counting 20-300 open passages observed on photographs of representative structures on both sides of the membrane, using a particle size analyzer (Carl Zeiss, type TG2-3). It appeared that pore size distributions are Gaussian, so that an average pore size and a standard deviation can be defined.

The average pore size throughout a membrane was determined by porometry. Membranes or layers from the commercial filter were soaked with a special inert solvent (Porofi; Coulter Electronics GMBH, Krefeld, Germany) to fill all pores. A Coulter porometer (Coulter Electronics, type I) was used to measure the pressure increase that is needed to remove the fluid from the sample. With the porometer the average pore size can be automatically calculated from the pressure curve. All measurements were carried out in triplo.

The porosity, or pore volume fraction, of the membranes was determined in duplo from the weight and volume of dry samples. Sample volumes were calculated from the membrane thickness, as averaged from five measurements (SEM). For calculating the porosity, the density of air was neglected compared to the density of PU $\left(1.13 \mathrm{~kg} / \mathrm{m}^{3}\right.$, according to the manufacturer).

\section{Characterization of the filter surface}

X-ray photoelectron spectroscopy (XPS) was used to analyze the elemental composition of the filter surfaces. Samples were arbitrarily cut from representative layers, obtained by section of the filter into separate membranes or nonwoven layers. XPS measurements were performed with a Kratos XSAM 800 (Kratos analytical, Manchester, $\mathrm{UK}$ ), using $\mathrm{X}$-rays from a $\mathrm{Mg}-\mathrm{K}_{\alpha}$ source $(15 \mathrm{kV} / 20 \mathrm{~mA})$ at a take-off angle of $90^{\circ}$ between the filter surface and the analyzer. Under these conditions, the detection depth was about $7 \mathrm{~nm}$. For quantitative analysis, detail scans were made of the $\mathrm{C} 1 \mathrm{~s}, \mathrm{O} 1 \mathrm{~s}$, and N1s peaks (diameter of the spot size $3 \mathrm{~mm}$ ). empirically derived sensitivity factors were used to convert peak areas in surface elemental composition.

Solid PU and PET films were used as reference samples. Solid PET films (Lux Thermanox 5410, Miles Scientific Laboratories, Naperville, USA) were cleaned by two-fold sonication in dichloromethane and acetone respectively. Solid PU films were cast from a $10 \%(\mathrm{w} / \mathrm{v})$ solution of the PU in tetrahydrofuran, and cleaned by two-fold sonication in cyclohexane and ethanol, respectively, essentially as previously described. ${ }^{13}$ Clean solid films $(2 \times 2 \mathrm{~cm})$ were coated with PEI by immersing the films for $1 \mathrm{~h}$ in a solution of $1 \%(\mathrm{w} / \mathrm{v})$ PEI in distilled water. Weakly adsorbed PEI was removed by three-fold sonication in PBS and distilled water respectively.

\section{PEI desorption}

The stability of the PEI coating on PU membrane filters was studied using ${ }^{14} \mathrm{C}$-labeled PEI $\left({ }^{14} \mathrm{C}\right.$-PEI), which was prepared by reductive methylation of PEI with ${ }^{14} \mathrm{C}$-formaldehyde (NEN Research Products, 's Hertogenbosch, The Netherlands) according to a procedure described by Okahata and Kunitake. ${ }^{23}$ The reaction was performed by adding $0.5 \mathrm{mmol}{ }^{14} \mathrm{C}$ formaldehyde $(0.25 \mathrm{mCi})$ and $8 \mathrm{mmol}$ formic acid to a solution of $50 \mathrm{~mL}$ of $4 \%(\mathrm{w} / \mathrm{v})$ PEI in water. The mixture was refluxed for $48 \mathrm{~h}$. After completion of the reaction, ${ }^{14} \mathrm{C}$-PEI was separated from unreacted formaldehyde by dialysis against water. The product was concentrated by freeze-drying. The labeling reaction resulted in the incorporation of 6-7 methyl groups per molecule PEI, i.e., approximately $0.5 \%$ of the total number of amine groups in PEI was methylated. The ${ }^{14} \mathrm{C}$-PEI had a specific activity of $0.1 \mathrm{mCi} / \mathrm{g}$ PEI.

Polyurethane membrane filters were modified with ${ }^{14} \mathrm{C}$-PEI and dried according to the procedure described in the filter modification section. Desorption of ${ }^{14} \mathrm{C}$-PEI from the modified filters was tested by slowly perfusing $(0.5 \mathrm{~mL} / \mathrm{sec})$ the filters with successive $500 \mathrm{~mL}$ aliquots of solutions used in filtration experiments. For this purpose, PBS, 0.5\% $(\mathrm{w} / \mathrm{v})$ human albumin in PBS, and $10 \%(\mathrm{v} / \mathrm{v})$ human plasma in PBS were used in succession. To determine the amount of ${ }^{14} \mathrm{C}$-PEI desorbed from the filter, samples of $2 \mathrm{~mL}$ were taken from the eluent and added to $18 \mathrm{~mL}$ AquaLuma (Hicol, Oud-Beijerland, The Netherlands). The radioactivity of these samples was measured using a liquid scintillation counter (LKB-Wallac, Rackbeta 1219). To determine the amount of ${ }^{14} \mathrm{C}$-PEI remaining in the filter after the different rinsing procedures, the filter materials were removed from the filter holder, and separated into six layers. Each layer was cut in small pieces, and added to $18 \mathrm{~mL}$ of AquaLuma. The radioactivity of these samples was measured by liquid scintillation counting. After correction for background radiation, the amount of ${ }^{14} \mathrm{C}-\mathrm{PEI}$ bound to the filter was calculated, and expressed as a function of the eluted volume.

The extent of ${ }^{14} \mathrm{C}$-PEI surface coverage was also determined for solid PU surfaces. Solid PU films were prepared and modified as described in the surface characterization section. The radioactivity of the solid ${ }^{14} \mathrm{C}$-PEI modified films was measured as described for the membrane filters in the previous section.

\section{Granulocytes}

Granulocytes were isolated from freshly collected citrated human blood, as described previously. ${ }^{13}$ One unit $(500 \mathrm{~mL})$ of blood was centrifuged at $400 \mathrm{~g}$ for 
$5 \mathrm{~min}$, followed by separation of the leukocyte and platelet rich interface (buffy coat) from the plasma layer and the packed red cells. The buffy coat was diluted with PBS, containing $13 \mathrm{mM}$ trisodium citrate and $0.5 \%(\mathrm{w} / \mathrm{v})$ human albumin (medium-G; 290295 mOsm, pH 7.2-7.4) to a final volume of $200 \mathrm{~mL}$, and layered on a Percoll (Pharmacia, Uppsala, Sweden) suspension with a specific gravity of $1.077 \mathrm{~g} / \mathrm{mL}$. Leukocytes were fractionated by centrifugation for $20 \mathrm{~min}$ at $1000 \mathrm{~g}$ (room temperature). The cells from the pellet formed below the Percoll layer wee collected. In order to lyse erythrocytes, cells were resuspended in ice-cold ammonium chloride medium (155 $\mathrm{mM} \mathrm{NH}_{4} \mathrm{Cl}, 10 \mathrm{mM} \mathrm{KHCO}_{3}$, and $0.1 \mathrm{mM}$ EDTA; 295 mOsm, pH 7.4). To complete the lysis, the suspension was gently shaken for $20 \mathrm{~min}$ while kept on ice. To remove red cell stroma and hemoglobin, the suspension was centrifuged at $4^{\circ} \mathrm{C}$ for $5 \mathrm{~min}$ at $400 \mathrm{~g}$ and the granulocyte containing pellet was resuspended in medium-G. This procedure was repeated 3 times.

The remaining granulocyte suspension was adjusted to $1.0 \times 10^{6}$ cells $/ \mathrm{mL}$ in medium-G, and characterized using a flow cytometer (Technicon, type H1). The purity of the granulocytes was always higher than 95\%. Monocytes were the main contaminants. The viability of the cell suspensions was always more than $97 \%$, as was determined by trypan blue exclusion. It was shown with monoclonal antibodies against B13.9 antigen, which is upregulated from secondary and tertiary granules in the granulocyte membrane upon activation, ${ }^{24}$ that the cells were not activated during the isolation step. Before being used in filtration experiments, leukocyte suspensions were stored at room temperature for not more than $1 \mathrm{~h}$.

\section{Packed red blood cells (RBC)}

Blood from healthy human donors was collected in blood bags containing citrate-phosphate-dextroseadenine (CPDA). After storage for $10-15 \mathrm{~h}$ at $20^{\circ} \mathrm{C}$, the bags were centrifuged for $10 \mathrm{~min}\left(3600 \mathrm{~g}\right.$ at $\left.20^{\circ} \mathrm{C}\right)$ to separate the plasma from the packed blood cells (RBC). After removal of supernatant plasma approximately $300 \mathrm{~mL}$ of RBC was diluted with $150 \mathrm{~mL}$ of an aqueous solution containing $0.9 \%$ sodium chloride (saline) to a hematocrit of $\sim 60 \%$. The cell suspension thus prepared contained most of the red cells, platelets, and leukocytes present in the original unit of blood. Filtration experiments were performed within $16 \mathrm{~h}$ after blood collection.

\section{Filtration procedure}

Filtration experiments with membrane filters were carried out using the system schematically depicted in Figure 1. The difference in height between the reservoirs and the filter was approximately $60 \mathrm{~cm}$. The hydrostatic pressure was kept constant during filtration. Before filtration, filters were first rinsed with $500 \mathrm{~mL}$ of saline to repel air and to wet the filter surface. The flow was then adjusted with saline in the range of $0.04-1 \mathrm{~mL} / \mathrm{sec}$, by means of a valve connected to the filter outlet. Filtration was started by connecting the blood cell reservoir to the filter. In case of RBC filtration the initial flow decreased rapialy due to the high viscosity of the cell suspension as compared to saline, but remained constant after filtration of approximately $20 \mathrm{~mL}$. The initial flow did not change when purified granulocyte suspensions were used. During filtration samples of the filtrate, typically $10 \mathrm{~mL}$ aliquots, were collected and analyzed. All experiments with modified and unmodified membrane filters were carried out in pairs, i.e., one cell suspension was used for both experiments. Replicate experiments were carried out 4 times.

Filtration experiments with commercial leukocyte filters were carried out according to blood bank standard procedures. ${ }^{7}$ Before filtration, the filters were rinsed with $200 \mathrm{~mL}$ of saline. RBC was then filtered at a standard blood flow of approximately $0.4 \mathrm{~mL} / \mathrm{sec}$. After filtration of one unit of RBC, the filter was rinsed with $100 \mathrm{~mL}$ of saline to recover red blood cells from the filter bed. The complete filtrate was collected and analyzed. Replicate experiments were performed 6 times.

\section{Analysis of the filtrate}

Purified granulocyte suspensions were analyzed using a micro cell counter (Sysmex, model F-800), following standard procedures. Total leukocyte counts in blood samples were determined with a Coulter counter (Coulter Electronics, type ZF/C1000). Aliquots of $20 \mu \mathrm{L}$ were diluted with $10 \mathrm{~mL}$ electrolyte containing solution. Lysis was induced with 2 drops of a saponin containing electrolyte solution. Remaining particles were then counted in $0.5 \mathrm{~mL}$ lysate sample. Measurements were carried out in in duplo.

Since the detection limit of the Coulter counter does not allow the detection of leukocyte counts less than $100 / \mu \mathrm{L}$, a flow cytometric technique was used to detect leukocytes in samples obtained after filtration experiments with commercial filters. ${ }^{25}$ This technique was also used to count cells of different leukocyte subpopulations. In experiments with symmetric membrane filters, however, relative concentrations of monocytes, lymphocytes, and granulocytes in blood samples were determined microscopically, after staining with May-Grünwald/Giemsa dye.

\section{Analysis of the filter materials after filtration}

After filtration, some membrane filters were used for further evaluation. When experiments were 
performed with purified granulocyte suspensions, filter samples were prepared for scanning electron microscopy (SEM). After filtration, the filters were fixed by slow perfusion with a solution of $2 \%(\mathrm{v} / \mathrm{v})$ glutaraldehyde in PBS for $10 \mathrm{~min}$. The filter materials were then detached from the filter housings, and dried in air. Small samples, cut from the membranes, were dehydrated by immersion for $10 \mathrm{~min}$ in successively 25,50 , and $75 \%$ ethanol in water, and twice in $98 \%$ ethanol. After drying in a vacuum desiccator the samples were sputter-coated with gold and examined by means of a scanning electron microscopy (JEOL, type JSM $35 \mathrm{CF}$ ) using a $15 \mathrm{kV}$ accelerating voltage.

Samples were prepared for light microscopy by taking small parts (about $1 \mathrm{~cm}^{2}$ ) from the filters, which were then fixed with formaldehyde containing solution as described elsewhere. ${ }^{6}$ Fixed samples were embedded in methacrylate resin, according to standard procedures. Sections of $7 \mu \mathrm{m}$ were cut with a microtome. After staining with hematoxilin solution (Delafield; Merck, Darmstadt, Germany), the samples were studied with a light microscope (Leitz, Ortholux II POL-BK).

\section{RESULTS AND DISCUSSION}

\section{Filter preparation and modification}

Filter preparation and characterization

SEM micrographs of the membranes used in this study (Fig. 2) show open and cellular pore structures, with relatively narrow pore size distributions as compared to nonwoven structures of commercial filters (Fig. 3). Pore sizes determined with the Coulter porometer, which represent the average pore size throughout the membranes $\left(d_{\mathrm{av}}\right)$, were in reasonable agreement with the pore sizes measured at both sides of the membrane surface using SEM ( $d_{\text {bottom }}, d_{\text {top }}$ ) (Table I). This finding demonstrates the symmetric nature of the membranes. Consequently, in further experiments no distinction was made between top and bottom side of the membranes.

The surface elemental composition of the membranes was routinely determined using XPS (Table II). When the results of XPS measurements were compared for different samples, it should be remembered
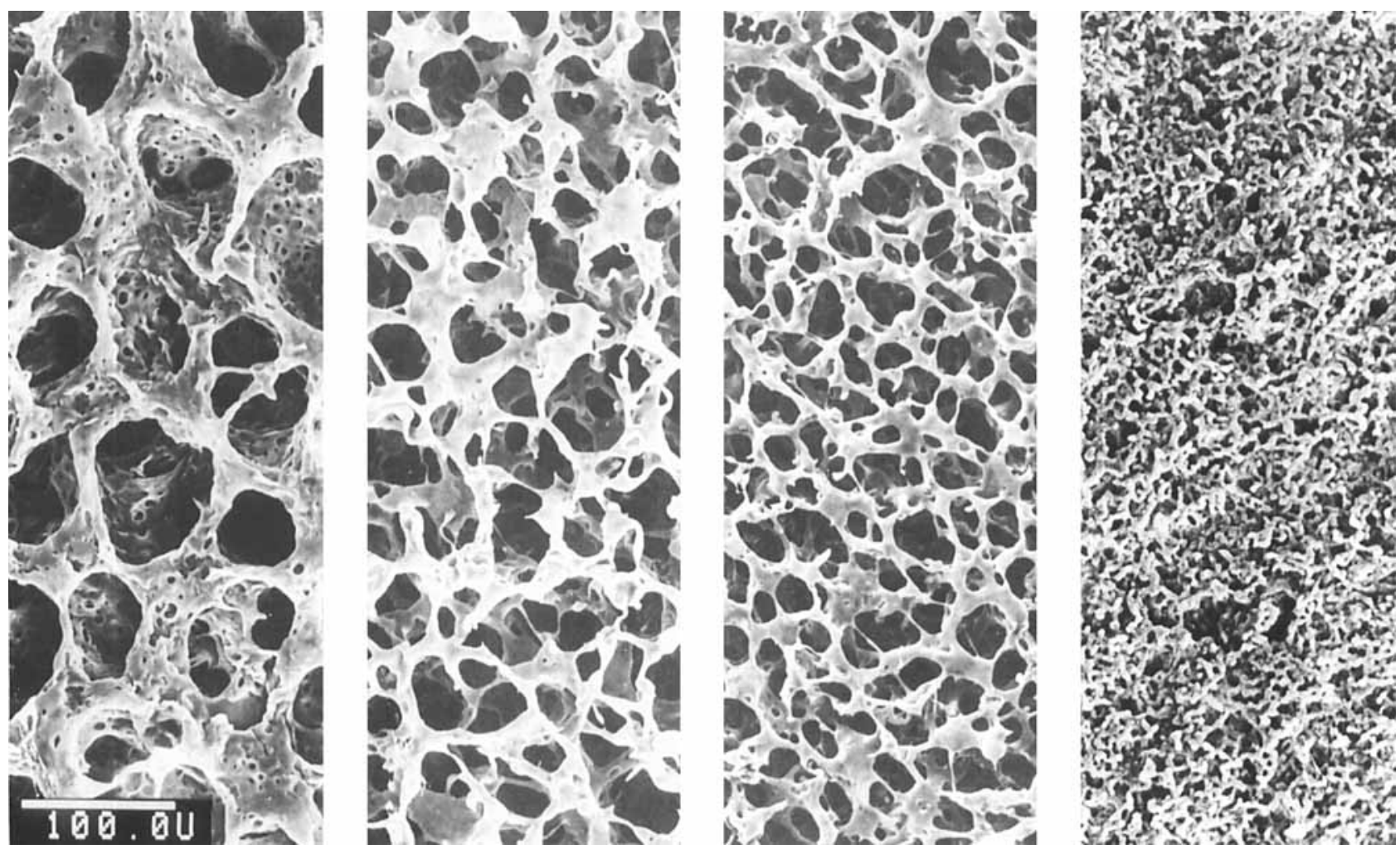

Figure 2. SEM micrographs of the top side of membranes used in this study. From left to right, the micrographs show membrane type 15.4 , type 15.3 , type 15.2 , and 15.1 . Original magnification $200 \times$. 

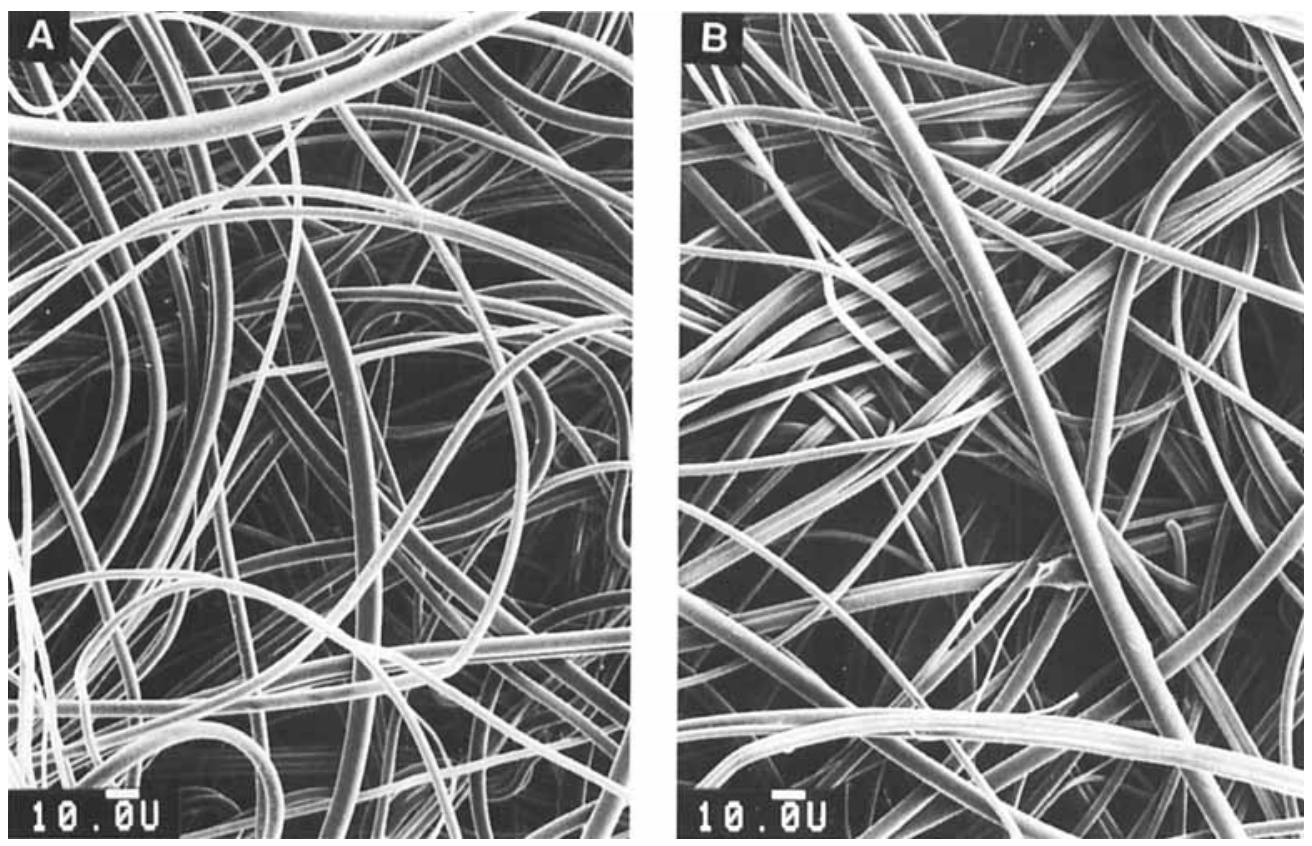

Figure 3. SEM micrographs of representative filter layers (coarse) from commercial filters used in this study, either unmodified (A) or PEI modified (B). Original magnification $400 \times$.

that empirically derived sensitivity factors were used to calculate the relative elemental composition of the sample surface. These sensitivity factors were derived for smooth solid surfaces, whereas the membrane surfaces were porous. Surface porosity may substantially affect the average take-off angle of emitted electrons, thereby influencing the detection depth. Strictly, a correction for the sample porosity should be made to allow a direct comparison of samples with different morphologies. Since we were not able to make such corrections, the XPS data for different kind of samples should be compared with some reservations. Never- theless, the surface elemental composition of porous PU membranes $(\sim 80 \% \mathrm{C}, \sim 18 \% \mathrm{O}, \sim 2 \% \mathrm{~N})$ agreed well with the surface composition of solid PU films.

Commercial filters, composed of PET fibers, were also characterized by XPS (Table II). The surface composition found for solid control films of PET agreed well with theoretical composition of PET $(71.4 \% \mathrm{C}$, $28.6 \% \mathrm{O}$ ). A large deviation of this theoretical composition was, however, found for the surface of PET fibers in filters. Probably the PET fibers in these filters, as obtained from the manufacturer, were not completely pure. It has been reported that the surface

TABLE II

Surface Elemental Composition (XPS) of Filter Materials Used

\begin{tabular}{|c|c|c|c|c|c|c|}
\hline \multirow[b]{2}{*}{ Sample } & \multicolumn{3}{|c|}{ After Washing With Water [At.-\%] } & \multicolumn{3}{|c|}{ After PEI Modification [At.-\%] } \\
\hline & C & $\mathrm{O}$ & $\mathrm{N}$ & C & $\mathrm{O}$ & $\mathrm{N}$ \\
\hline PU film* & 79.6 & 18.1 & 2.4 & 72.8 & 22.7 & 3.8 \\
\hline PET film* & 72.6 & 27.4 & 0.0 & 71.5 & 22.7 & 5.8 \\
\hline 13 & 76.9 & 20.6 & 2.5 & 77.4 & 17.5 & 5.1 \\
\hline 14 & 76.6 & 21.1 & 2.2 & 76.1 & 19.3 & 4.6 \\
\hline 15.1 & 77.1 & 20.7 & 2.1 & 74.8 & 18.2 & 7.0 \\
\hline 15.2 & 75.9 & 21.8 & 2.3 & 74.1 & 20.3 & 5.1 \\
\hline 15.3 & 76.6 & 21.4 & 2.0 & 75.6 & 20.6 & 3.8 \\
\hline 15.4 & 77.3 & 20.2 & 2.5 & 74.9 & 20.1 & 5.0 \\
\hline 16 & 76.9 & 21.1 & 2.0 & 75.6 & 21.0 & 3.4 \\
\hline Fine $^{t}$ & 66.5 & 33.3 & 0.2 & 69.0 & 22.5 & 8.5 \\
\hline Coarse $^{\dagger}$ & 67.8 & 31.9 & 0.3 & 69.0 & 22.2 & 8.8 \\
\hline
\end{tabular}

\footnotetext{
*Solid control film surfaces.

${ }^{\dagger}$ Representing nonwoven layers from coarse and fine filter sections of the commercial PET filters used.
} 


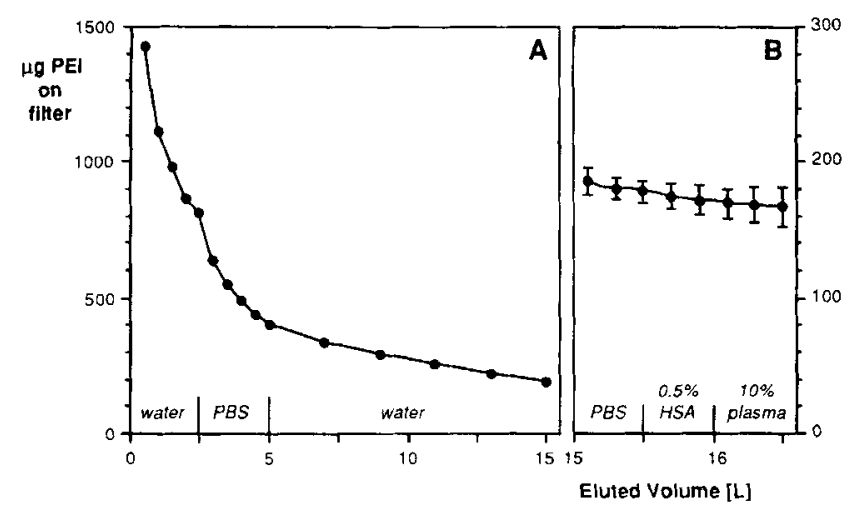

Figure 4. Amount of ${ }^{14} \mathrm{C}-\mathrm{PEI}$ bound to the surface of a PU membrane filter (type 14, total filter volume $\sim 12 \mathrm{~mL}$ ) during washing steps following the modification procedure (curve A), and during successive perfusion with PBS, $0.5 \%(\mathrm{w} / \mathrm{v})$ albumin in PBS, and $10 \%(\mathrm{v} / \mathrm{v})$ plasma in PBS after a model filtration experiment (curve B). Error bars are standard deviations $(\mathbf{n}=3)$.

concentration of oxygen at the surface of drawn PET fibers is enhanced by surface oxidation during the drawing process. $^{26}$

\section{PEI modification}

Treatment of the filters with a solution of $1 \%(\mathrm{w} / \mathrm{v})$ PEI in water led to the adsorption of PEI to the filter material. To remove excessive and weakly bound PEI from the filters, rinsing with PBS and water was performed. The efficiency of this procedure was tested for a PU membrane filter with the use of ${ }^{14} \mathrm{C}$-labeled PEI $\left({ }^{14} \mathrm{C}\right.$-PEI). It appeared that the amount of ${ }^{14} \mathrm{C}$-PEI in the filter rapidly decreased during the initial stage of the rinsing procedure, but leveled off after rinsing the filter with $15 \mathrm{~L}$ of water, i.e., $>1000$ times the void volume of the filter (Fig. 4a). When the modified membrane filters were mounted in clean housings, no significant desorption of ${ }^{14} \mathrm{C}$-PEI occurred during successive perfusion with PBS, $0.5 \%(\mathrm{w} / \mathrm{v})$ human albumin in PBS, and 10\% human plasma in PBS (Fig. 4B). The amount of ${ }^{14} \mathrm{C}$-PEI adsorbed to the surface of solid PU films also did not change after rinsing with solutions containing albumin or plasma (Fig. 5).

Apparently, PEI was bound very tightly to PU surfaces, and was not significantly displaced by adhesive plasma proteins present in the media used. In the literature, the adsorption of PEI to solid surfaces is generally characterized by high affinity type Langmuir isotherms. ${ }^{27-29}$ Lindquist and Stratton have reported that strong attractive forces between PEI and colloidal silica cause adsorbed PEI molecules to spread on the silica. ${ }^{28} \mathrm{~A}$ spread form of adsorbed PEI molecules was also found by Horn, who studied the adsorption of PEI to polystyrene latex particles. ${ }^{29}$ Hostetler and Sanson found that PEI molecules ad- sorbed to silica gel within a surface area that was close to the area calculated from the gyration radius of the PEI molecules used in solution. ${ }^{30}$ The high affinity binding of PEI to various surfaces has generally been explained by electrostatic interactions, ${ }^{18,31-33}$ but also nonionic or hydrophobic interactions have been suggested. ${ }^{18,33-35}$ In specific cases, the adsorption of PEI to a PET surface ${ }^{36}$ or a sulfated polethylene surface $^{32}$ has been ascribed to the effects of hydrogen bonding. Probably a combination of different kind of interactions attributes to the strong adsorption of PEI on the present filter surfaces.

The surface concentration of PEI adsorbed onto the PU membrane filters can be estimated. Assuming an average pore size of $30 \mu \mathrm{m}$ for the membrane filter used (Table I, type 14) and a total filter volume of $12 \mathrm{~mL}$ (diameter $50 \mathrm{~mm}$, thickness $6 \mathrm{~mm}$ ), and using an equation for the relation between specific surface $(S)$ and average pore diameter $\left(d_{\mathrm{av}}\right)$ of foams, $S=4 / d_{\mathrm{av}}$, as derived by Aubert, ${ }^{37}$ the accessible surface for PEI adsorption in the complete filter is approximately $1.6 \mathrm{~m}^{2}$. Then, a coverage of $\sim 0.1 \mathrm{mg} \mathrm{PEI} / \mathrm{m}^{2}$ of membrane surface can be calculated. This result agrees well with the amount of ${ }^{14} \mathrm{C}$-PEI that had been adsorbed under comparable conditions to the surface of a solid PU film in a control experiment $\left(\sim 0.12 \mathrm{mg} / \mathrm{m}^{2}\right.$, Fig. 5). In the literature, surface coverage varying from $0.1-0.5 \mathrm{mg} \mathrm{PEI} / \mathrm{m}^{2}$, mainly depending on the molecular weight of the PEI, is generally interpreted in terms of a monolayer adsorption. ${ }^{28-30}$ It is therefore likely that nearly a complete coverage of the filter surfaces with PEI has been achieved here. It cannot be excluded, however, that small uncovered areas may also occur.

\section{Filter characterization after modification}

The results of XPS (Table II) demonstrate a significant increase of the concentration of nitrogen at the surface of PEI modified membrane filters as compared to unmodified membrane filters, apparently caused by incorporation of amine groups. Remarkably, the surface nitrogen concentration for porous PEI modified membranes was generally found to be higher than for PEI modified solid films. It is likely that the removal of weakly bound PEI from the surface was more effective for solid films than for porous membranes. To remove weakly bound PEI from solid films, PEI treated films were sonicated in PBS and distilled water for several times. It turned out in practice, however, that this procedure damaged the porous structure of the membranes. Therefore, a rinsing procedure was used to remove weakly bound PEI from the membranes. The fact that relatively high concentrations of nitrogen were found on membranes with relatively small pores (e.g., membrane type 15.1, Table II) suggests that the efficiency of the rinsing procedure increased with the pore size of the membrane. This 
finding is probably explained by the tendency of the washing solvent to flow through the largest pores in the membrane filter. ${ }^{38}$ The occurrence of this process, generally known as 'channelling,' may explain that a relatively high concentration of nitrogen was found for membrane type 15.4. Although the average pore size of this membrane was large, small micropores were observed in the polymer matrix (Fig. 2). Such micropores, which may retain some weakly bound PEI, were probably formed by a liquid-liquid phase demixing process during the membrane preparation procedure, ${ }^{39}$ and can clearly be distinguished from the large macropores that were formed after leaching out the salt particles in the membrane.

The concentration of nitrogen at the surface of PEI modified commercial filter materials and the solid PET films was significantly higher as compared to PU filters and solid films. This finding suggests that a larger amount of PEI adsorbed to materials composed of PET than to materials composed of PU. It should be kept in mind, however, that the results of XPS measurement for samples with different surface morphologies cannot be compared properly.

Modification of the filters with PEI did not lead to significant changes of the porous structure in the filters. The pore sizes in PEI modified filters are in reasonable agreement with pore sizes in unmodified filters, as was found by measurements with the Coulter porometer and SEM (Table I). Moreover, SEM examination of the modified filters did not reveal any changes of the surface morphology, such as fiber interconnection, etching, or surface roughening (Fig. 3). Based on these results, it is assumed that the sieving capacity of unmodified and PEI modified filters is equal. Nevertheless, their surface properties with respect to leukocyte adhesion are substantially different.

\section{Filtration experiments}

Filtration of granulocyte suspensions using membrane filters

We have previously studied the adhesion of granulocytes from various media to unmodified and PEI modified surfaces of solid PU films under controlled flow conditions. ${ }^{15}$ Although the absolute number of adherent granulocytes was largely influenced by the composition of the medium, the extent of adhesion was always larger with PEI modified surfaces as compared to unmodified surfaces. To test whether the PEI coating could be used to improve the depletion of granulocytes with leukocyte filters, suspensions of purified granulocytes in medium- $G$ were filtered through unmodified and PEI modified membrane filters. The conditions in these experiments were better controlled as compared to whole blood filtration experiments, because the cellular composition of the

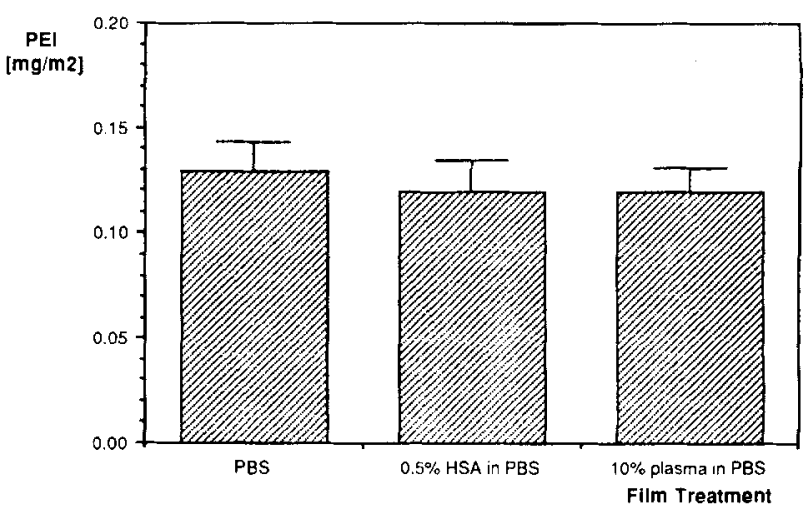

Figure 5. Amount of ${ }^{14} \mathrm{C}-\mathrm{PEI}$ present at the surface of PEI modified solid PU films after treatment for $15 \mathrm{~min}$ by sonication in PBS, 0.5\% (w/v) albumin in PBS, and $10 \%$ $(\mathrm{v} / \mathrm{v})$ plasma in PBS. Error bars are standard deviations $(\mathbf{n}=4)$.

suspension was exactly known and the influence of red cells, platelets, and plasma on the filtration process was excluded. In order to minimize the effects of mechanical trapping of cells in the filter pores, symmetric membrane filters in which the average pore size was large (type $16 ; d_{\mathrm{av}} \sim 25 \mu \mathrm{m}$ ) as compared to the diameter of granulocytes $\left(5-8 \mu \mathrm{m}^{40}\right)$ were used.

The depletion of granulocytes by unmodified and PEI modified membrane filters was measured as a function of the filtered volume. More than $95 \%$ of the granulocytes were initially removed by the PEI modified filter, whereas the depletion of cells by the unmodified filter $(\sim 80 \%)$ was significantly lower (Fig. 6). This finding can be explained by differences between the numbers of adherent cells to the filter membranes, because the porous structure of both filters was the same. When filtration experiments were performed at a higher flow rate of $0.20 \mathrm{~mL} / \mathrm{sec}$, instead of $0.04 \mathrm{~mL} / \mathrm{sec}$, the depletion of granulocytes by both membrane filters was substantially lower (Fig. 7). This effect of flow on the removal of cells by the membrane filters confirmed the importance of cell adhesion phenomena in these experiments. When the flow rate is increased, the residence time of cells in the membrane filter is decreased and as a consequence the chance of a cell to effectively collide with the surface of the filter is reduced. A similar effect of flow on leukocyte retention in columns of siliconized glass beads was reported by others. ${ }^{41}$

SEM examination of the membrane filters after filtration confirmed that the granulocytes were depleted by adhesion to the membrane filter surface in both filter types. Mechanical trapping of the cells by small pores or dead spaces in the membrane filters was not observed. No significant differences in cell morphology were observed between granulocytes adherent to the surfaces of unmodified (Fig. 8[A]) and PEI modified membranes (Fig. 8[B]). 


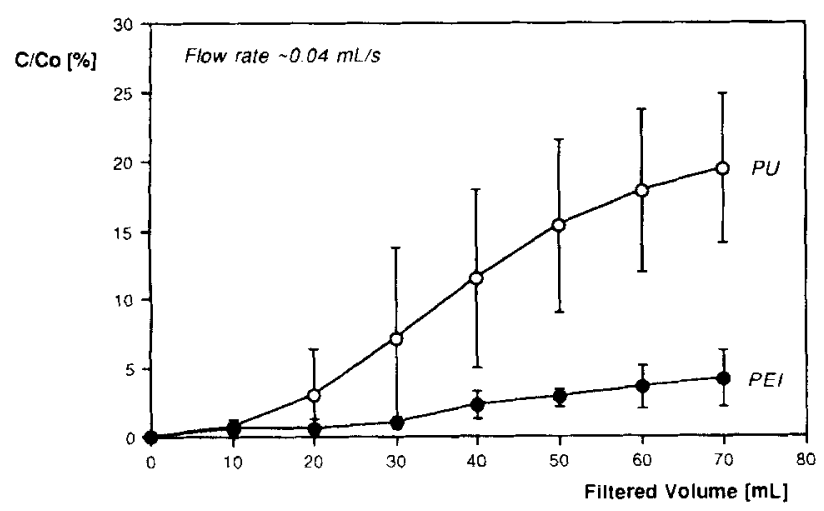

Figure 6. Recovery of granulocytes in the filtrate after filtration of granulocytes in medium-G through unmodified (open circles) and PEI modified (closed circles) membrane filters (type 16), flow rate $0.04 \mathrm{~mL} / \mathrm{sec}$. Graphs show the percentage of granulocytes in the filtrate $\left(100 \times \mathrm{C}_{\text {out }} / \mathrm{C}_{\text {in }}\right)$ as a function of filtered volume \pm $\mathrm{SD}(\mathrm{n}=4)$.

It is of interest to compare the extent of cell adhesion to the membrane filters with the extent of cell adhesion to unmodified and PEI modified solid films, which were previously used under static ${ }^{13}$ and flow conditions. ${ }^{15}$ For the present experiments it was calculated that the ratio between the number of adherent cells in the PEI modified filters and in the unmodified filters was approximately 1.2 for both flow rates, whereas the effect of the PEI coating on the extent of cell adhesion was significantly higher in our previous experiments. Apparently, the efficiency of the PEI coating to improve cell adhesion to the membrane filter is relatively low. This is probably due to a poor interaction between the granulocytes and the filter membranes. The absence of red cells in the cell suspension used in the present experiments diminishes the driving force of granulocytes to mi-

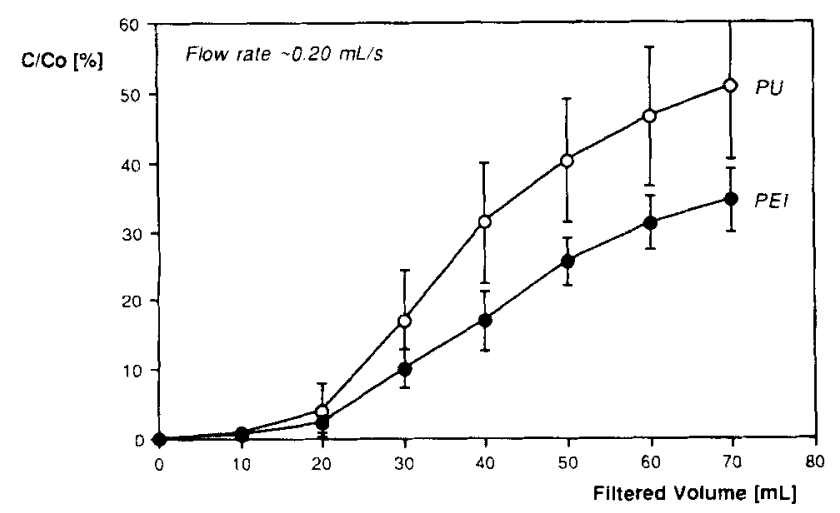

Figure 7. Recovery of granulocytes in the filtrate after filtration of granulocytes in medium-G through unmodified (open circles) and PEI modified (closed circles) membrane filters (type 16), flow rate $0.20 \mathrm{~mL} / \mathrm{sec}$. Graphs show the percentage of granulocytes in the filtrate $\left(100 \times \mathrm{C}_{\text {out }} / \mathrm{C}_{\text {in }}\right)$ as a function of filtered volume \pm $\operatorname{SD}(n=4)$. grate and adhere to the filter membranes. ${ }^{42,43}$ When granulocytes reach the filter surface under these circumstances, the contact time between the cell and the surface will only be short as a result of the irregular structure in the membrane filters. We have previously reported that the difference between the adhesion of granulocytes to unmodified and PEI modified surfaces of solid films is relatively small at short exposure times, as compared to longer exposure times. ${ }^{13}$

In conclusion, the results of filtration experiments with granulcoytes prove that the PEI coating can lead to an increase of the extent of leukocyte adhesion during the filtration process, which may result in an improved filter efficacy. The effect of PEI to enhance leukocyte adhesion to membrane filters is, however, small as compared to leukocyte adhesion to solid film surfaces.

Filtration of whole blood using membrane filters

The effect of PEI coating on the efficiency of leukocyte filters under standard filtration conditions was studied, using both symmetric (type 13; $d_{\mathrm{av}} \sim 20 \mu \mathrm{m}$ ) and asymmetric membrane filters (type $15 ; d_{\mathrm{av}}$ $10-60 \mu \mathrm{m})$. The results of these experiments showed large variations, probably due to differences in the composition of blood collected from different donors. The total population of leukocytes in human whole blood generally varies between $4 \times 10^{6}$ and $11 \times 10^{6}$ cells $/ \mathrm{mL}$, and also the composition of this population, i.e., granulocytes $\left(2-6 \times 10^{6} \mathrm{~mL}^{-1}\right)$, lymphocytes $\left(1.5-4 \times 10^{6} \mathrm{~mL}^{-1}\right)$, and monocytes $(0.2-$ $\left.0.8 \times 10^{6} \mathrm{~mL}^{-1}\right)$, may vary largely. ${ }^{44}$ These variations are likely to affect the filtration efficiency since different subpopulations of leukocytes are known to adhere to polymer surfaces to different extents. ${ }^{13,14,41}$ Also variations in the amount and type of other blood components may influence the efficiency of the filtration process. Red cells may play a role in the migration of leukoctyes to solid surfaces under conditions of flow, ${ }^{42,43}$ and platelets may be involved in the adhesion of leukocytes to solid surfaces. ${ }^{45,46}$ Moreover, the presence of plasma proteins in the cell suspension medium is known to inhibit leukocyte adhesion. ${ }^{47,48}$ In order to avoid the effects of variations of different RBC suspensions, unmodified and PEI modified membrane filters were tested with the same RBC suspension in replicate experiments on 4 different days.

Figure 9 shows the recovery of leukocytes in the filtrate after filtration of $\mathrm{RBC}$ by unmodified and PEI modified symmetric filters as a function of the filtered volume. No significant differences were found between the unmodified and the PEI modified filter with respect to the recovery of leukoctyes in the collected filtrate $(P=.4$; two-tailed $t$ test for paired data sets). To study the depletion of different leuko- 

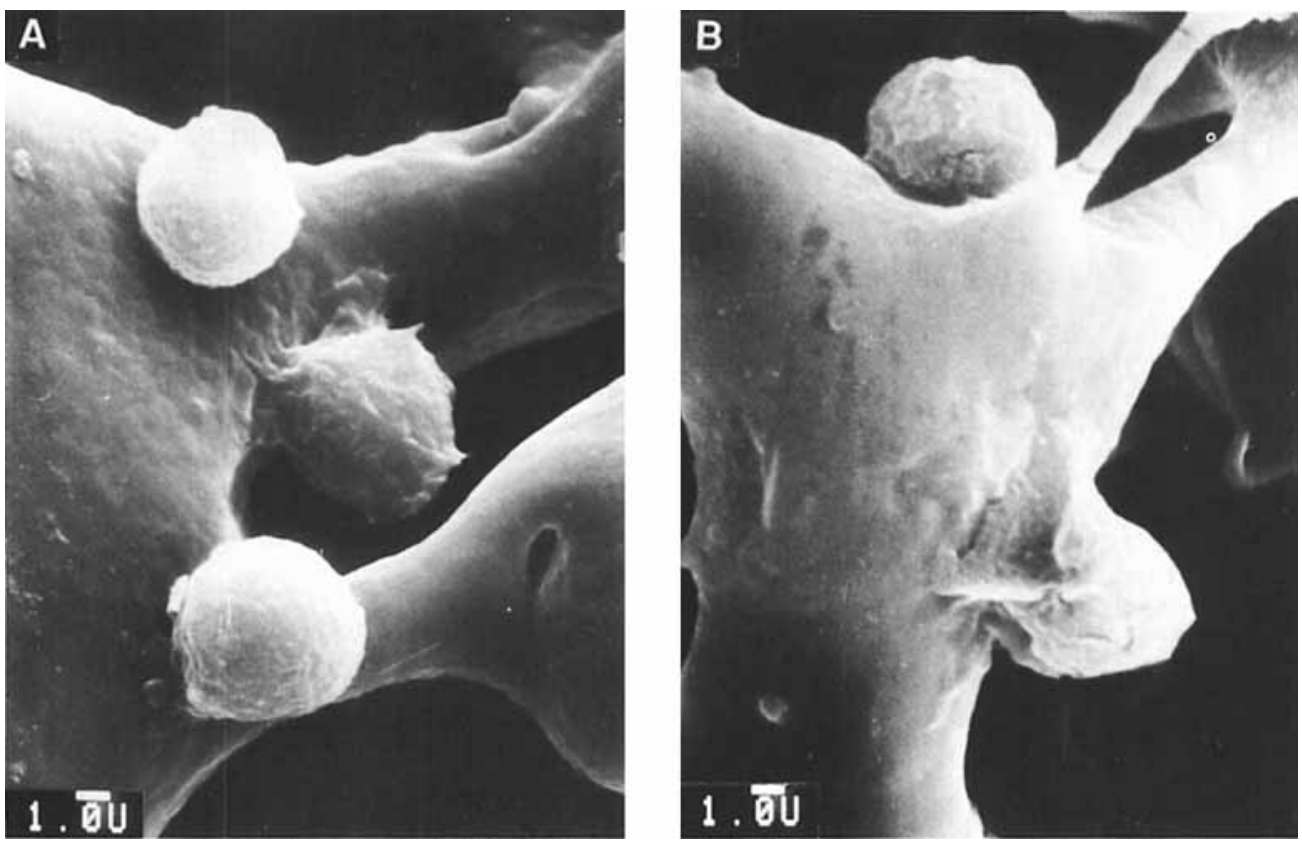

Figure 8. SEM micrographs of granulocytes depleted in the middle section of unmodified (A) and PEI modified (B) membrane filters (type 16), after filtration of a suspension of granulocytes in medium-G at a flow rate of $0.20 \mathrm{~mL} / \mathrm{sec}$. Original magnification $4000 \times$.

cyte subpopulations in detail, $70 \mathrm{~mL}$ of the filtrate was collected and analyzed to detect the amounts of granulocytes, lymphocytes, and monocytes. It was found that the removal of these subpopulations from RBC by the filters was largely dependent on the cell type (Fig. 10). In general, the symmetric membrane filters depleted more than $80 \%$ of the granulocytes, whereas the depletion of lymphocytes was less than $30 \%$. This finding suggests that the efficiency of the filter depends on the extent of cell adhesion to the filter surface, since the recovery of different leukocyte populations was consistent with their adhesiveness to polymer surfaces reported in the literature. ${ }^{41,49}$ Relatively high concentrations of lymphocytes in filtered blood, as compared to other leukocyte types, have also been reported by other authors. ${ }^{12,50,51}$ However, the difference between the unmodified and PEI modified filters with regard to the recovery of granulocytes $(P=.13)$, lymphocytes $(P=.29)$, and monocytes $(P=.26)$ in the filtrate was not significant (two-tailed $t$ tests for paired results). Apparently the PEI coating did not lead to a substantial increase of the number of leukocytes adhered to the membrane filter under the blood filtration conditions used in this study.

The results of a histological study of filter sections after filtration confirmed the contribution of adhesion of leukocytes in the filtration process. Figure 11 shows that leukocytes adhered to the surface of the membrane filters. No substantial differences were observed, however, between the unmodified (Fig. 11[A]) and the PEI modified membrane filters (Fig. 11[B]) with respect to the type, number, and morphology of adherent cells. In general, large numbers of cells, mainly granulcoytes, were found to adhere to the upper parts of the filters, whereas almost no leukocytes were depleted in the bottom section of the filters. These findings are in agreement with our previous studies on the distribution of adherent cells in membrane filters. ${ }^{12}$

Standard blood filtration experiments were also performed with asymmetric membrane filters. The average pore size of these filters gradually decreased from approximately $60-10 \mu \mathrm{m}$ in the direction of blood flow. The asymmetric nature of the filter allows

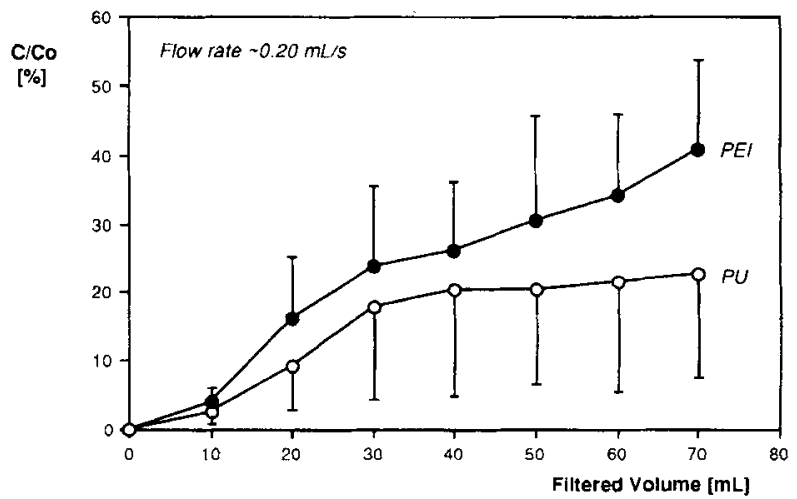

Figure 9. Recovery of leukocytes (total) in the filtrate after filtration of RBC through unmodified (open circles) and PEI modified (closed circles) membrane filters (type 13). Flow rate $0.20 \mathrm{~mL} / \mathrm{sec}$. Graphs show the percentage of leukocytes in the filtrate $\left(100 \times \mathrm{C}_{\text {out }} / \mathrm{C}_{\mathrm{in}}\right)$ as a function of filtered volume $\pm \mathrm{SD}(n=4)$. For clearness, error bars are plotted in one direction only. 


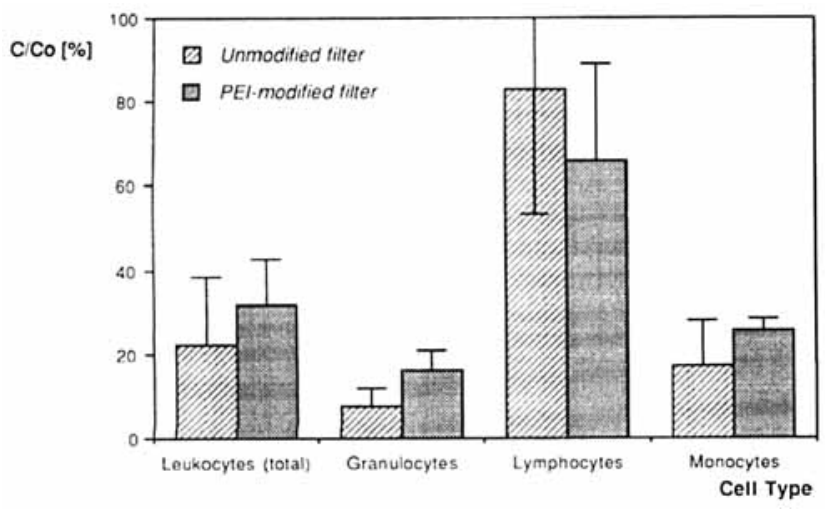

Figure 10. Recovery of different leukocyte subpopulations in the collected filtrate $(70 \mathrm{~mL})$ after filtration of RBC through symmetrical membrane filters (type 13), either unmodified (left bars) and PEI modified (right bars). Bars show the percentage of cells in the collected filtrate $\left(100 \times \mathrm{C}_{\text {out }} / \mathrm{C}_{\mathrm{in}}\right) \pm \mathrm{SD}$, as determined microscopically $(n=4)$.

a very close contact between cells and the filter surface in the bottom section, whereas early stage clogging of the filter is prevented by partial removal of cells in the top section. ${ }^{12}$ Adhesion of cells to the filter surface during the filtration was promoted by providing a relatively long residence time for the cells in the filter (flow $\sim 0.04 \mathrm{~mL} / \mathrm{sec}$ ). Figure 12 shows the recovery of different types of leukocytes in the collected filtrate after filtration of $70 \mathrm{~mL}$ of RBC by unmodified and PEI modified asymmetric filters. The close contact between the leukocytes and the asymmetric filter surface resulted in a relatively high removal of leukocytes as compared to symmetric filters. However, again no statistical significance between the difference in leukocyte removal by unmodified and PEI modified filters was obtained.

Filtration of whole blood using commercial filters

Commercial leukocyte filters, composed of PET fibers, were used to evaluate the perspectives of the PEI coating in routine blood filtration. These filters were developed to remove at least $99 \%$ of the leukocytes in one unit $(\sim 400 \mathrm{~mL})$ of $R B C$ suspension. Filtration experiments were performed with unmodified and PEI modified filters, according to standard procedures used in blood banks to prepare leukocyte poor red cell concentrates. The results of these experiments show that more than $99.9 \%$ of the leukocytes in the RBC suspension were removed by the unmodified filters (Fig. 13). PEI coating of the filters did not significantly increase the extent of leukocyte removal by the filters ( $P \geq .26$; two-tailed $t$ test for paired results). Relatively less granulocytes as compared to lymphocytes were removed by the commercial filters, which is in contrast with the results obtained with the membrane filters used in this study. This diffidence is probably caused by the specific construction of the commercial filters, in which large amounts of lymphocytes can be efficiently removed by mechanical sieving in the bottom section of the filter. ${ }^{7}$ Lymphocytes are known to be less deformable as compared to granulocytes, ${ }^{52}$ and may thus easily be captured in small pores.

Evaluation of the filter behavior

The inability of PEI modified filters to improve the removal of leukocytes from blood was unexpected. We
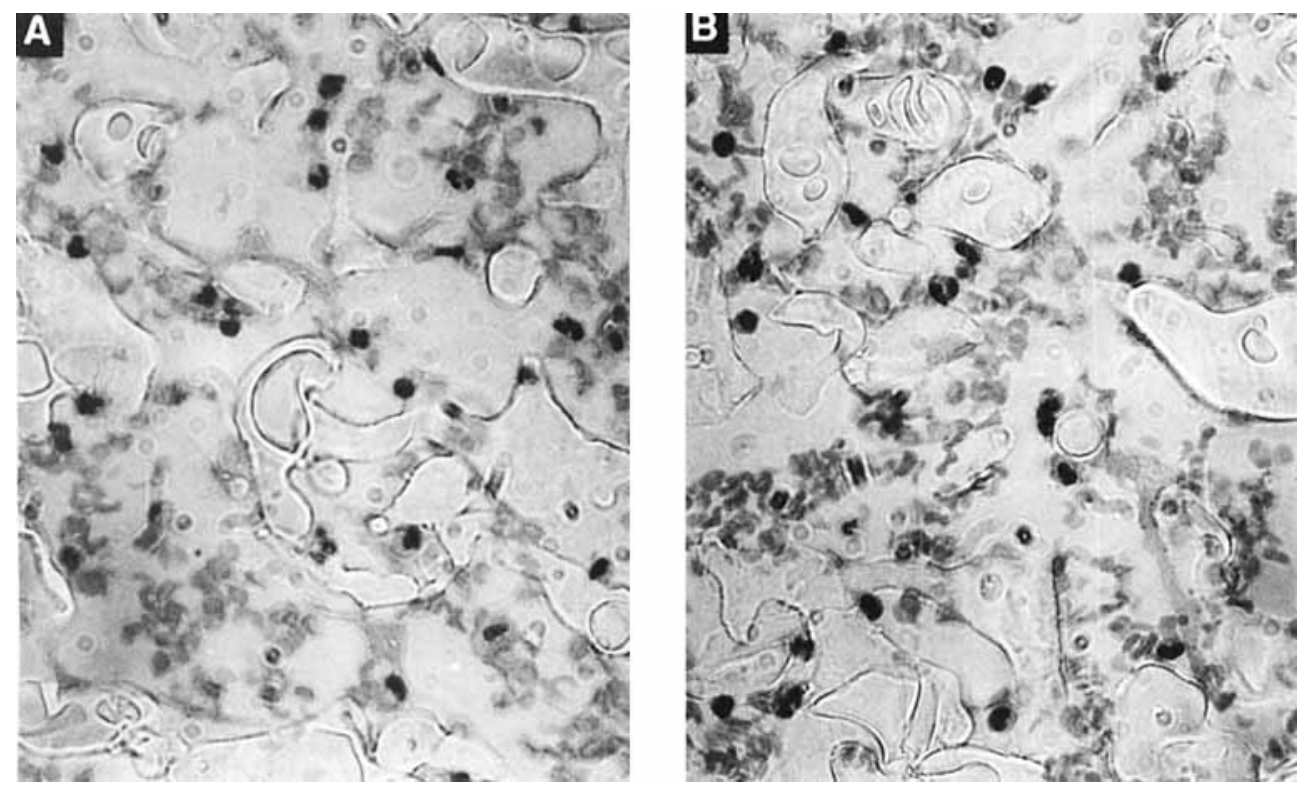

Figure 11. Stained cross sections of the middle part of membrane filters (type 13), unmodified (A) and PEI modified (B), after filtration of RBC. Original magnification $350 \times$. 


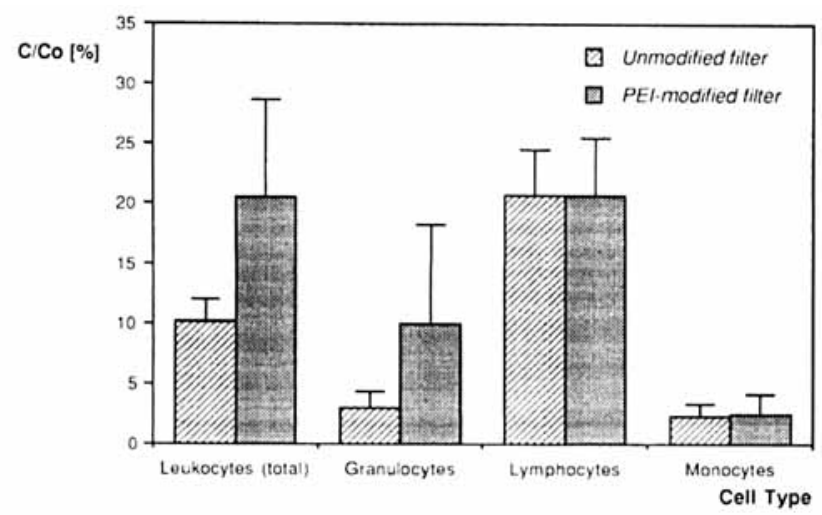

Figure 12. Recovery of different leukocyte subpopulations in the collected filtrate $(70 \mathrm{~mL})$ after filtration of RBC through asymmetrical membrane filters (type 15), either unmodified (left bars) and PEI modified (right bars). Bars show the percentage of cells in the collected filtrate $\left(100 \times \mathrm{C}_{\text {out }} / \mathrm{C}_{\text {in }}\right) \pm \mathrm{SD}$, as determined by flow cytometry $(n=4)$.

have previously studied the adhesion of leukocytes from medium-G to unmodified and PEI modified solid PU films under static conditions. ${ }^{13}$ It appeared that the number of adherent cells to PEI modified surfaces was approximately three times higher than on unmodified surfaces. Subsequently, we have investigated whether the enhancing effect of the PEI coating on leukocyte adhesion to solid films could be extended under conditions of flow. ${ }^{15}$ The results of this study again showed a difference between unmodified and PEI modified solid PU films with respect to leukocyte adhesion. Finally, we have tested the PEI modified solid films under conditions similar to those in standard blood filtrations, i.e., flow, in the presence of red cells, platelets, and citrated plasma diluted in saline. ${ }^{15}$ It turned out that the number of adherent leukocytes on PEI modified solid PU films was still five times higher than on unmodified solid films, although the extent of adhesion was substantially reduced in the presence of plasma.

In contrast to these previous experiments with solid films under flow conditions, no enhancing effect of the PEI coating on adhesion was found when leukocyte adhesion was studied with porous membranes under flow conditions. To explain this inconsistency, the effect of flow rate on leukocyte adhesion should be considered. For solid films, a maximum in cell adhesion was found when the shear rate was $30 \mathrm{sec}^{-1} .15$ The shear rate $(\tau)$ in the present membrane filters was estimated by assuming laminar flow $(\nu)$ of the blood through nontortuous capillaries with a length of $6 \mathrm{~mm}$ and a uniform diameter $(d)$ of $25 \mu \mathrm{m}$, and using an equation, $\tau=8 \cdot \nu / d$, derived from the well known Poiseuille-Hagen equation..$^{53}$ Thus, an approximate shear rate in the filters of $\sim 30 \mathrm{sec}^{-1}$ was achieved by adjusting the flow rate to $0.20 \mathrm{~mL} / \mathrm{sec}$. Because of the large limitations of the flow rate calculations,

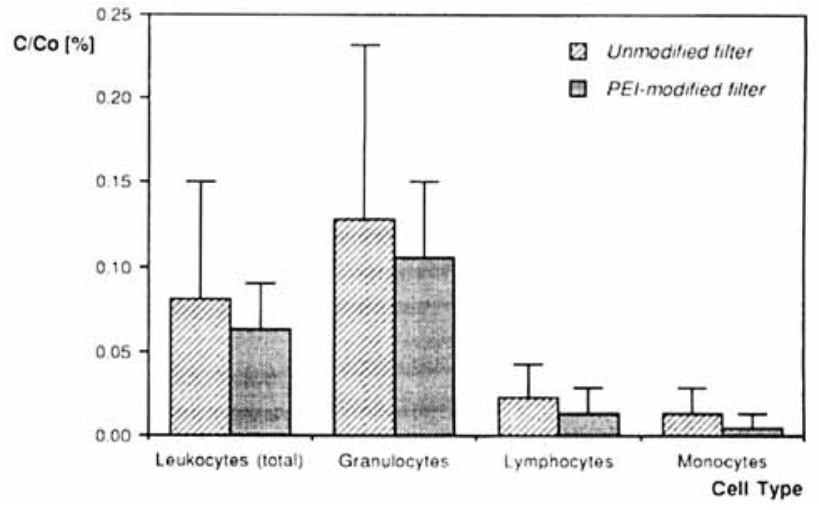

Figure 13. Recovery of different leukocyte subpopulations in the collected filtrate $(500 \mathrm{~mL})$ after filtration of RBC through commercial leukocyte filters, either unmodified (left bars) and PEI modified (right bars). Bars show the percentage of cells in the collected filtrate $\left(100 \times \mathrm{C}_{\text {out }} / \mathrm{C}_{\mathrm{in}}\right) \pm \mathrm{SD}$, as determined by flow cytometry $(n=6)$.

and the complicated flow patterns in the filters as compared to the laminar flow in the experiments previously described, ${ }^{15}$ an experimental determination of the optimal flow rate in filters is preferred. It should be noted, however, that an optimal flow rate is not a prerequisite for enhanced leukocyte adhesion to PEI modified filters since the effect of PEI to promote cell adhesion to solid films was also observed at other flow rates. ${ }^{15}$ It is therefore not very likely that the inability of the PEI coating to improve the efficiency of leukocyte filters is due to a nonoptimized flow rate in these filters.

It is more likely that the difference between the results of the present filtration experiments and previously described adhesion experiments with the smooth surface of the solid films is due to the porous structure of the membrane filters. It is well known that cell adhesion depends on the curvature and texture of the substrate. ${ }^{47}$ For instance, it has been reported that the adhesion of platelets ${ }^{54}$ and erythrocytes ${ }^{55}$ to porous surfaces was diminished as a result of fluid flow through pores. On the other hand, fibroblasts adhere more firmly to porous surfaces as compared to solid surfaces. ${ }^{56}$

Also surface roughness is known to affect cell adhesion. Chang et al. have reported that the extent of erythrocyte adhesion to a number of substrates was affected by surface irregularities. ${ }^{57}$ Rich and Harris found that macrophages preferentially adhere to rough surfaces as compared to smooth surfaces under flow conditions. ${ }^{58}$ Similar effects of surface roughness have been reported for the adhesion of platelets by Zingg et al..$^{59}$ Guidoin et al. have recognized the effects of surface roughness in blood filters, ${ }^{60}$ and found that large numbers of adherent leukocytes and platelet aggregates were formed in macroaggregate filters with an irregular and imperfect surface texture, 
as compared to filters with a smooth surface. The effect of surface roughness on cell adhesion has been attributed to the presence of gas nuclei and bubbles at rough surfaces, which may enhance cell adhesion. ${ }^{61}$ Air nuclei at rough surfaces, which are preferentially formed at hydrophobic substrates, are known to activate the complement system, ${ }^{62}$ which mediates the adhesion of leukocytes to artificial surfaces. ${ }^{63,64}$ Less is known about the surface roughness in the present filters, but it is very likely that microscopic irregularities at the surface of the tested membranes (Fig. 2) may have influenced leukocyte adhesion during filtration.

It should be noted that the surface to blood volume ratio in filters is large as compared to solid films. Since the extent of complement activation is proportional to the surface area exposed to blood, ${ }^{65}$ the effect of complement activation on leukocyte adhesion may become significant in blood filters. ${ }^{66,67}$ The large surface to blood volume ratio in filters may also cause activation of platelets. Activated platelets secrete adhesive proteins such as fibrinogen, fibronectin, and von Willebrand factor, ${ }^{45,46}$ which may be adsorbed on the surface of both unmodified and PEI modified filters.

Effects of the filter structure may even counteract the effect of PEI. For example, since PEI modified PU surfaces are hydrophilic as compared to unmodified PU surfaces, ${ }^{13}$ the formation of air nuclei in filters, which may favor the adhesion of leukocytes to the filter surface, may be promoted in unmodified filters. The various effects of the filter structure on leukocyte adhesion may diminish the effect of the PEI coating on leukocyte adhesion in filters. In this context, the direct influence of the physicochemical properties of the filter material surface on leukocyte adhesion in filters may possibly be overestimated.

\section{CONCLUSIONS}

The main objective of this study was to investigate the role of leukocyte adhesion in the leukocyte filtration process. For this purpose we used a PEI surface modification procedure to prepare filters that were structurally identical, but had different surfaces properties with respect to leukocyte adhesion in vitro. The present results confirm that adhesion of leukocytes on the filter material is important for removal of leukocytes, but an effect of the PEI coating on the extent of leukocyte adhesion was only significant when red cells, platelets, and plasma were absent in the filtration medium. This finding suggests that factors other than the physicochemical properties of the filter surface dominate leukocyte adhesion in the filters. In this respect, we recommend that the influence of filter surface texture on leukocyte adhesion, e.g., shape, roughness, tortuosity, and porosity, be further investigated.

This work was supported by the Nederlands Produktietielaboratorium voor Bloedtransfusie-apparatuur en Infusievloeistoffen BV (NPBI), Emmer-Compascuum, The Netherlands. The authors acknowledge Prof. I. A. Feuerstein for stimulating discussions. Furthermore, they thank Tineke Palfenier and Henk Veldman of the Central Laboratory of the Blood Transfusion Service of the Netherlands Red Cross (CLB), Amsterdam, The Netherlands, for their assistance in the blood filtration experiments.

\section{References}

1. P. Rebulla, F. Bertolini, A. Parravicini, and G. Sirchia, "Leukocyte-poor blood components: a purer and safer transfusion product for recipients?" Transfusion Med. Rev., 4, Suppl. 1, 19-23 (1990).

2. H.T. Meryman and M. Hornblower, "The preparation of red cells depleted of leukocytes-Review and evaluation," Transfusion, 26, 101-106 (1986).

3. S. F. Goldmann, F. Heiss, and I. Scheinert, "Removal of buffy coat from stored ACD blood by dextran agglomeration and subsequent filtration," Vox Sang., 25, 470-473 (1973)

4. K. Kayashima, Y. Asanuma, J.W. Smith, M. Blumenstein, P.S. Malchesky, R. Valenzuela, and Y. Nosé, "Simple on-line filters for the therapeutic removal of lymphocytes from blood," Trans. Am. Soc. Artif. Intern. Organs, 27, 559-562 (1981).

5. G. Sirchia, A. Parravicini, P. Rebulla, N. Greppi, M. Scalamogna, and F. Morelati, "Effectiveness of red blood cells filtered through cotton wool to prevent antileukocyte antibody production in multitransfused patients," Vox Sang., 42, 190-197 (1982).

6. I. Steneker and J. Biewenga, "Histochemical and immunohistochemical studies on the preparation of leukocyte-poor red cell concentrates by filtration: the filtration process on cellulose acetate filters, "Vox Sang., 58, 192-198 (1990).

7. I. Steneker and J. Biewenga, "Histochemical and immunohistochemical studies on the preparation of white cell-poor red cell concentrates by filtration: the filtration process using three different polyester filters," Transfusion, 31, 40-46 (1991).

8. E. L. Snyder, L. DePalma, and P. Napychank, "Use of polyester filters for the preparation of leukocytepoor platelet concentrates," Vox Sang., 54, 21-23 (1988).

9. R. Reverbi and C. Menini, "Clinical efficacy of five filters specific for leukocyte removal," Vox Sang., 58, 188-191 (1990).

10. T.S. Kickler, W. Bell, P.M. Ness, H. Drew, and D. Pall, "Depletion of white cells from platelet concentrates with a new adsorption filter," Transfusion, 29, 411-414 (1989).

11. B. Wenz, "Clinical and laboratory precautions that reduce the adverse reactions, alloimmunization, infectivity, and possibly immunomodulation associated with homologous transfusions," Transfusion Med. Rev., 4, Suppl. 1, 3-7 (1990).

12. A. Bruil, W.G. van Aken, T. Beugeling, J. Feijen, I. Steneker, J.G. Huisman, and H.K. Prins, "Asymmetric membrane filters for the removal of 
leukocytes from blood," J. Biomed. Mater. Res., 25, 1459-1480 (1991).

13. A. Bruil, J. G. A. Terlingen, T. Beugeling, W. G. van Aken, and Jan Feijen, "In vitro leukocyte adhesion to modified polyurethane surfaces. I. Effect of ionizable functional groups," Biomaterials, 13, 915-923 (1992).

14. A. Bruil, L.M. Brenneisen, J.G. A. Terlingen, T. Beugeling, W. G. van Aken, and J. Feijen, "In vitro leukocyte adhesion to modified polyurethane surface. II. Effect of wettability," J. Colloid Interface Sci., (submitted).

15. A. Bruil, J.I. Sheppard, J. Feijen, and I. A. Feuerstein, "In vitro leukocyte adhesion to modified polyurethane surfaces. III. Effect of flow, fluid medium, and platelets on PMN adhesion," J. Biomed. Sci. Polymer Edn., (accepted).

16. H. Moroson and M. Rotman, "Biomedical applications of polycations," in Polyelectrolytes and Their Applications, A. Rembaum and E. Sélégny (eds.), Reidel Publishing Company, Dordrecht, Holland, 1975 , p. 187.

17. K. C. Watts, O. A. N. Hussain, J. H. Tucker, M. Stark, P. Eason, G. Shippey, D. Rutovitz, and G. T. B. Frost, "The use of cationic polyelectrolytes in the preparation of cell monolayers for automated cell scanning and diagnostic cytopathology," Anal. Quant. Cytol., 6, 272-278 (1984).

18. S.F. D'Souza and N. Kamath, "Cloth bioreactor containing yeast cells immobilized on cotton cloth using polyethyleneimine," Appl. Microbiol. Biotechnol., 29, 136-140 (1988).

19. T. Tashiro, "Removal of Escherichia coli from water by systems based on insoluble polystyrenepoly(ethylene glycol)s, -polyethylenimines, and -polyethylenepolyamines quarternized," J. Appl. Pol. Sci., 43, 1369-1377 (1991).

20. R. J. Mayfield, M. Lipson, and I. M. Morgan, "Cigarette filters for the selective removal of ciliatoxic smoke components," AU Patent, 469193, Australia (1972).

21. T. Sata and R. Izuo, "Modification of transport properties of exchange membrane. XI. Electrodialytic properties of cation exchange membranes having polyethyleneimine layer fixed by acid-amide bonding," J. Appl. Pol. Sci., 41, 2349-2362 (1990).

22. M. Huang, L. Metherel, and O.P. Rorstad, "Utility of polycation-treated filters for the assay of receptors for VIP," J. Receptor Res., 8, 831-838 (1988).

23. Y. Okahata and T. Kunitake, "Catalysis by polymer complexes. VIII. Enhanced nucleophilic reactivity of hydroxamate anions bound to quaternized polyethyleneimines and related compounds," J. Pol. Sci. Pol. Chem., 16, 1865-1881 (1978).

24. P. A. T. Tetteroo, M. J. E. Bos, F. J. Visser, and A. E. G. von dem Borne, "Neutrophil activation detected by monoclonal antibodies," J. Immunol., 136, 3428-3432 (1986).

25. E. J. M. Al, S. C. E. Visser, H. K. Prins, R. N. I. Pietersz, H.W. Reesink, and J.G. Huisman, "A flow cytometric method for determination of white cell subpopulations in filtered red cells," Transfusion, 31, 835-842 (1991).

26. N. Chand, "XPS study of drawn polyethyleneterephtalate fibers," Popular Past. Rubber, 26, 6-10 (1981).

27. W.A. Kindler and J.W. Swanson, "Adsorption kinetics in the polyethyleneimine-cellulose fiber system," J. Pol. Sci., A2, 9, 853-865 (1971).
28. G.M. Lindquist and R.A. Stratton, "The role of polyelectrolyte charge density and molecular weight on the adsorption and flocculation of colloidal silica with polyethyleneimine," J. Colloid Interface Sci., 55, 45-59 (1976).

29. D. Horn, "Polyethyleneimine-physicochemical properties and applications," in Polyamines and Polyquarternary Ammonium Salts, E. J. Goethals (ed.), Pergamon Press, 1980, p. 333.

30. R. E. Hostetler and J.W. Swanson, "Diffusion into and adsorption of polyethyleneimine on porous silica gel," J. Pol. Sci. Pol. Chem. Ed., 12, 29-43 (1974).

31. G. G. Allan, K. Akagane, A. N. Neogi, W. M. Reif, T. Mattila, "Physical entrapment of polyelectrolytes within microporous solids: the 'jack-in-the-box' effect," Nature, 225, 175-176 (1970).

32. N. Larsson, P. Steinius, J. C. Eriksson, R. Maripuu, and B. Lindberg, "ESCA studies of sulfated polyethylene surfaces modified by adsorption of polyethyleneimine and colloidal silica particles," J. Colloid Interface Sci., 90, 127-136 (1982).

33. O. Larm, R. Larsson, and P. Olsson, "A new nonthrombogenic surface prepared by selective covalent binding of heparin via a modified reducing terminal residu," Biomat. Med. Dev. Art. Org., 11, 161-173 (1983).

34. B. Alince, "Polyethyleneimine adsorption on cellulose," Cellulose Chem. Technol., 8, 573-590, (1974).

35. F. Th. Hesselink, "On the theory of polyelectrolyte adsorption - The effect on adsorption behavior of the electrostatic contribution to the adsorption free energy," J. Colloid Interface Sci., 60, 448-466 (1977).

36. G.U. Ostrovidova and V.B. Kopylov, "Characteristics of interaction of polyethyleneimine with poly(ethylene) terephtalate," Chem. Abstr., 106, 103193b (1987).

37. J.H. Aubert, "An objective characterization of the cell size of microcellular foams," J. Cell. Plast., 24, 132-145 (1988).

38. T.D. Brock, "Membrane structure and functioning," in Membrane Filtration, Springer Verlag, Berlin, 1983, p. 5.

39. W. L. J. Hinrichs, J. Kuit, J. Feijen, E. J. C. M. P. Lommen, and Ch. R.H. Wildevuur, "Controlled microporosity: a key design principle for artificial skin," in Medical Textiles for Implantation, H. Planck, M. Dauner, and M. Renardy (eds.), Springer-Verlag, Berlin, 1990, p. 293.

40. G.W. Schmid-Schönbein, "Morphometry of human leukocytes," Blood, 56, 866-875 (1980).

41. J.E. Garvin, "Factors affecting the adhesiveness of human leukoctyes and platelets in vitro," J. Exp. Med., 114, 51-73 (1961).

42. B. M. Fenton, R. T. Carr, and G. R. Cokelet, "Nonuniform red cell distribution in 20 to $100 \mu \mathrm{m}$ bifurcations," Microvasc. Res., 29, 103-126 (1985).

43. H. L. Goldsmith and S. Spain, "Margination of leukocytes in blood flow through small tubes," Microvasc. Res., 27, 204-222 (1987).

44. F. J. Baker and R. E. Silverton, "Introduction to haematology," in Introduction to Medical Laboratory Technology, Butterworths and Co., London, 1985, p. 305.

45. F. L. Rasp, C. C. Clawson, and J. E. Repine, "Platelets increase neutrophil adherence in vitro to nylon fiber," J. Lab. Clin. Med., 97, 812-819 (1981).

46. D. J. Morley and I. A. Feuerstein, "Adhesion of polymorphonuclear leukocytes to protein-coated and 
platelet adherent surfaces," Thromb. Haemost., 62, 1023-1028 (1989).

47. F. Grinnell, "Cellular adhesiveness and extracellular substrata," Int. Rev. Cytol., 53, 65-144 (1978).

48. J. V. Forrester and J. M. Lackie, "Adhesion of neutrophil leukocytes under conditions of flow," J. Cell Sci., 70, 93-110 (1984).

49. J. O. Lamvik, "Separation of lymphocytes from human blood," Acta Haemat., 35, 294-303 (1966).

50. D. R. Absolom, C. J. van Oss, and A.W. Neumann, "Elution of human granulocytes from nylon fibers by means of repulsive van der Waals forces," Transfusion, 21, 663-674 (1981)

51. J. Vakkila and G. Myllylä, "Amount and type of leukocytes in 'leukocyte-free' red cell and platelet concentrates," Vox Sang., 53, 76-82 (1987).

52. M. A. Lichtman and E. A. Kearney, "The filterability of normal and leukemic human leukocytes," Blood Cells, 2, 350-358 (1976).

53. H.H. Lipowsky, "Mechanics of blood flow in the microcirculation," in Handbook of Bioengineering, $\mathrm{R}$. Skalak and S. Chien (eds.), McGraw-Hill Book Company, New York, 1987, p. 18.16.

54. P. Predecki, L. Life, P. A. Russell, and M. M. Newman, "Prevention of platelet adhesion to porous surfaces," J. Biomed. Mater. Res., 14, 405-415 (1980).

55. D.R. Clarke, and J.B. Park, "Prevention of erythrocyte adhesion onto porous surfaces by fluid perfusion," Biomaterials, 2, 9-13 (1981).

56. A.F. von Reckum, "New aspects of biocompatibility," in Clinical Implant Materials, G. Heimke, U. Soltész, and A. J.C. Lee (eds.), Elsevier Science Publishers B. V., Amsterdam, 1990, p. 297.

57. G. Chang, D. R. Absolom, A. B. Strong, G. D. Strubley, and W. Zingg, "Physical and hydrodynamic factors affecting erythrocyte adhesion to polymer surfaces," J. Biomed. Mater. Res., 22, 13-29 (1988).

58. A. Rich and A.K. Harris, "Anomalous preferences of cultured macrophages for hydrophobic and roughned substrata," J. Cell Sci., 50, 1-7 (1980).

59. W. Zingg, A. W. Neumann, A. B. Strong, O.S. Hum, and D.R. Absolom, "Platelet adhesion to smooth and rough hydrophobic and hydrophilic surfaces under conditions of static exposure and laminar flow," Biomaterials, 2, 156-158 (1981).

60. R. Guidoin, K. Taylor, and W.H, Bain, "Blood filter evaluation," Biomat. Med. Dev. Art. Org., 5, 317-336 (1977).

61. C. A. Ward, B. Ruegsegger, D. Stanga, and W. Zingg, "Reduction in platelet adhesion to biomaterials by removal of gas nuclei," Trans. Am. Soc. Artif. Intern. Organs, 20, 77-85 (1974).

62. C. A. Ward, A. Koheil, W.R. Johnson, and P.N. Madras, "Reduction of complement activation from biomaterials by removal of air nuclei from the surface roughness," J. Biomed. Mater. Res., 18, 255-269 (1984).

63. G. A. Herzlinger and R. D. Cumming," Role of complement activation in cell adhesion to polymer blood contact surfaces," Trans. Am. Soc. Artif. Inter. Organs, 26, 165-171 (1980).

64. J. Hed, M. Johansson, and M. Lindroth, "Complement activation according to the alternative pathway by glass and plastic surfaces and its role in neutrophil adhesion," Immunol. Lett., 8, 295-299 (1984).

65. J. Breillatt and W.J. Dorson, "Hemocompatibility studies. Quantification of serum complement activation by polymeric membranes and materials," Asaio J., 7, 57-63 (1984).

66. D. G. Wright, J. C. Kauffmann, G. K. Terpstra, R. G. Graw, A. B. Deisseroth, and J. I. Gallin, "Mobilization and exocytosis of specific (secondary) granules by human neutrophils during adherence to nylon wool in filtration leukapheresis (FL)," Blood, 52, $770-782$ (1978).

67. E. L. Snyder, R. K. Root, B. McLeod, A. P. Dalmassa, "Activation of complement by blood transfusion filter," Vox Sang., 45, 288-293 (1983).

Received October 6, 1992

Accepted May 6, 1993 